\title{
Optimal coordinated design of PSS and UPFC-POD using DEO algorithm to enhance damping performance
}

\author{
Omar Muhammed Neda \\ Depertmant of Engineering Affairs, Sunni Diwan Endowment, Iraq
}

\begin{tabular}{l}
\hline \hline Article Info \\
\hline Article history: \\
Received Dec 1, 2019 \\
Revised May 18, 2020 \\
Accepted May 27, 2020 \\
\hline
\end{tabular}

\section{Keywords:}

Dolphin optimization Low-frequency oscillations Particle swarm optimization Power oscillation damping Unified power flow controller

\begin{abstract}
Low-frequency oscillations (LFO) are an inevitable problem of power systems and they have a great effect on the capability of transfer and power system stability. The power system stabilizers (PSSs) as well as flexible AC transmission system (FACTS) devices can help to damp LFO. The target of this study is to tackle the problem of a dual-coordinated design between PSS and unified power flow controller (UPFC) implementing the task of power oscillation damping (POD) controller in a single machine infinite bus (SMIB) system. So, dolphin echolocation optimization (DEO) technique is utilized as an optimization tool to search for optimal parameter tunings based on objective function for enhancing the dynamic stability performance for a SMIB. DEO an algorithm has a few parameters, simple rules, provides the optimum result and is applicable to a wide range of problems like other meta-heuristic algorithms. Use DEO gave the best results in damping LFO compared to particle swarm optimization (PSO) algorithm. From the comparison results between PSO and DEO, it was shown that DEO provides faster settling time, less overshoot, higher damping oscillations and greatly improves system stability. Also, the comparison results prove that the multiple stabilizers show supremacy over independent controllers in mitigationg LFO of a SMIB.
\end{abstract}

Copyright (C) 2020 Institute of Advanced Engineering and Science. All rights reserved.

\section{Corresponding Author: \\ Omar Muhammed Neda, \\ Department of Electrical Power Engineering, \\ Sunni Diwan Endowment, \\ Bagdad, Iraq. \\ Email: omar.neda88@gmail.com}

\section{INTRODUCTION}

Power system must provide power continuity, voltage, and frequency is constant to feed the loads all the time. To have service reliability, it is required to keep the synchronism of generators synchronization with sufficient capacity to fulfill the demand load. The problems of stability happen at the synchronization of the machines which are exposed to turbulence. When there is a change in mechanical torque or decrease damping torque, will happen LFO in the power grid. If the oscillations are now well damping this might increase the even-load magnitude and leads to lose synchronism, the operating capability, power system efficacy and power system stability also will be affected by LFO [1].

Power system stabilizers (PSSs) use for several decades and it was installing with the excitation system, i.e. automatic voltage regulator (AVR); to reduce affect AVR, damp the local oscillatory mode, improve power system damping, regulate voltage and enhance power system stability. The oscillations interarea occurred by large disturbances and long transmission line may be not needed in control of oscillations by PSS. Therefore, flexible ac transmission system (FACTS) devices were utilized for enhancing in addition to damping oscillations inter-area occurred by large disturbances [2].

FACTS devices are utilized in scheming the active besides reactive power flow in the transmission line, which have shown very emboldening results. The power transfer limited through modulation of bus 
voltage, reactance of transmission line, and damping oscillation promoting. Owing to the action external fast control related to FACTS operation of the device, therefore enhancement power system stability [3, 4$]$.

The most popular and essential FACTS device is UPFC. It combines the characteristic of two FACTS devices (i.e. SSSC and STATCOM). It can offer complete compensation, i.e. phase shifting in addition to voltage regulation, reactive as well as impedance compensation [5, 6]. Also, it is able to optimizing as well as controlling the power flow, system oscillation reduction, regulation of reactive power, and enhancing the system transient stability [7].

In order to enhance overall system performance, must coordination among PSS and UPFC-POD techniques utilized for damping LFO. Uncoordinated among POD and PSS caused destabilizing interactions and therefore, unstable be power system. To avoid the issue of interactions, a coordinated design is used to get the most benefits of multiple stabilizers. This decreases any probable negative interactions among the various-stabilizers and increases system stability. Numerous of researches have been presented for the coordination among PSS as well as FACTS-damping controller by utilizing a different method. Parameter tuning is the key problem in the coordinated among PSS and UPFC-POD simultaneously controller design for useful damping. The utilization of improvement methods for facilitated configuration must be speedy, productive. Accordingly, numerous strategies distinctive have been utilized to give the coveted composed plan and strength to various stabilizers, for example, the utilization of non-dominated sorting particle swarm optimization (NSPSO) [8], fuzzy logic [9] and chaotic optimization algorithm (COA) [10].

In this paper, a new algorithm use of a global optimal search that is based on echolocation, known as the dolphin echolocation optimization (DEO) technique. The DEO is utilized as an optimization tool to adjust the damping parameters for independently and dual damping controllers design on the basis of the eigenvalue objective function. Emulation of SMIB results prepared with UPFC denoted that the dual simultaneous coordination among PSS\&UPFC based-POD had better and faster damping capacity for Lessing LFO with lesser overshoot compared with the independent design, which improved the stability of SMIB system pointedly. In addition, DEO has given the better results in individual and coordinated design compared with PSO algorithm results.

\section{MODEL OF SMIB WITH UPFC}

Figure 1 shows a SMIB fitted with UPFC device [11]. Transmission line and UPFC are transferring electric power from the synchronous generator to the infinite bus. The UPFC formed of two voltage source converters (VSCs), that is VSC 1 and VSC 2 which are coupling through DC link capacitor, excitation transformer (ET), boosting transformer (BT) and control signals which are consists of four inputs to the UPFC [12]. These four input control signals are the modulation amplitude ratio $(\mathrm{mB}, \mathrm{mE})$ and control angle phase ratio $(\delta \mathrm{B}, \delta \mathrm{E})$ for every voltage source converter. DC voltage for two VSCs is providing via a common capacitor bank to maintain active power balance between two voltage converters. In this work, mE channel is modulated so as to coordinated design. VSC 1 is insert in parallel with the line via an (ET) and have two input control ( $\mathrm{mE}$ and $\delta \mathrm{E}$ ) which are used to regulate shunt voltage and DC-link capacitor voltage respectively. VSC 2 is attached to the conveyance line in series via an (BT) and have two input control ( $\mathrm{mB}$ and $\delta \mathrm{B})$ which are utilized for controlling active in addition to reactive power on the transmission line respectively. These four input control signals are utilized for providing synchronized power compensation in series line devoid of external source of voltage [13]. The system parameters are listed in Appendix.

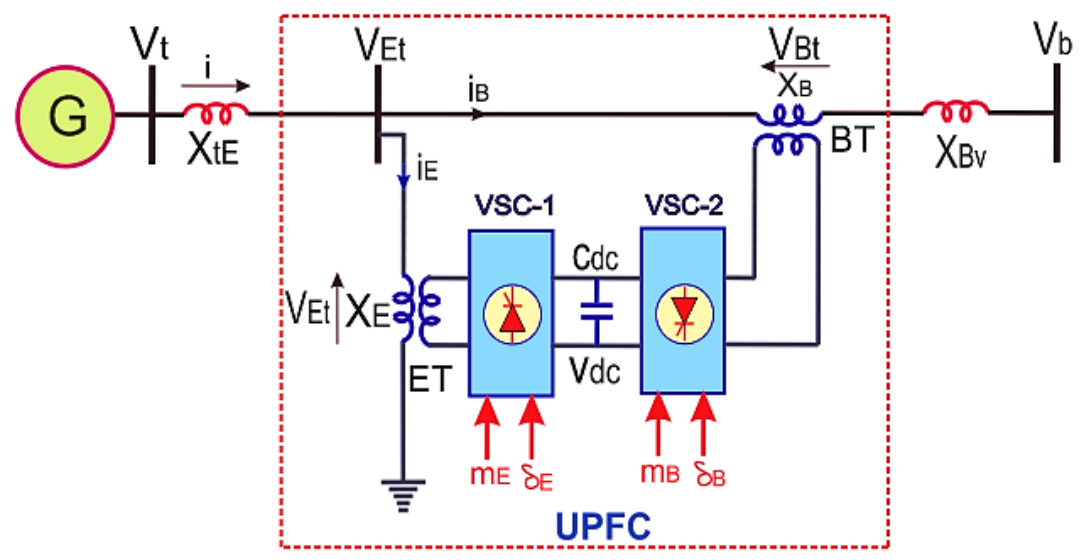

Figure 1. SMIB supplied with UPFC 


\subsection{Non-linear dynamic form of UPFC}

UPFC's dynamic performance is used as a one way to advance the power system's signal stability. Via neglects the resistance as well as transient of the UPFC transformers (i.e. ET, BT) and applying Park's transformation the UPFC can be modeled as follows [14]:

$$
\begin{aligned}
& {\left[\begin{array}{l}
v E \mathrm{td} \\
v E \mathrm{tq}
\end{array}\right]=\left[\begin{array}{cc}
0 & -\mathrm{xE} \\
x E & 0
\end{array}\right]\left[\begin{array}{l}
i \mathrm{Ed} \\
i \mathrm{Eq}
\end{array}\right]+\left[\begin{array}{ccc}
\frac{m E}{2 \mathrm{DC}} & \cos \delta E \\
2 & \\
\frac{m E}{2} & v \mathrm{DC} & \sin \delta E \\
2
\end{array}\right]} \\
& {\left[\begin{array}{l}
v B \mathrm{td} \\
v B \mathrm{tq}
\end{array}\right]=\left[\begin{array}{cc}
0 & -\mathrm{x} B \\
x B & 0
\end{array}\right]\left[\begin{array}{l}
i \mathrm{Bd} \\
i \mathrm{~Bq}
\end{array}\right]+\left[\begin{array}{ccc}
\frac{m B}{2} & v \mathrm{DC} & \cos \delta B \\
2 & \\
\frac{m B}{2} & v \mathrm{DC} & \sin \delta B \\
2
\end{array}\right]} \\
& \frac{\mathrm{d} \nu_{\mathrm{DC}}}{\mathrm{dt}}=\frac{3 \mathrm{~m}_{\mathrm{E}}}{4 \mathrm{C}_{\mathrm{DC}}}\left[\begin{array}{ll}
\cos \delta_{\mathrm{E}} & \sin \delta_{\mathrm{E}}
\end{array}\right]\left[\begin{array}{c}
\mathrm{i}_{\mathrm{Ed}} \\
\mathrm{i}_{\mathrm{Eq}}
\end{array}\right]+\frac{3 \mathrm{mB}_{\mathrm{B}}}{4 \mathrm{C}_{\mathrm{DC}}}\left[\begin{array}{ll}
\cos \delta_{\mathrm{B}} & \sin \delta_{\mathrm{B}}
\end{array}\right]\left[\begin{array}{c}
\mathrm{i}_{\mathrm{Bd}} \\
\mathrm{i}_{\mathrm{Bq}}
\end{array}\right]
\end{aligned}
$$

where, VE, XE and iE are voltage, reactance and current of excitation respectively. VB, $\mathrm{XB}$ and iB are voltage, reactance and current of boosting respectively. VDC and CDC are the voltage and capacitance of DC-link.

\subsection{SMIB non-linear form} Figure 1 [15]:

In (4), (5), (6), and (7) represents the non-linear dynamic for SMIB system which presented in

$$
\begin{aligned}
& \dot{\delta}=\omega b(\omega-1) \\
& \dot{\omega}=\frac{1}{M}(P m-P e-D(\omega-1)) \\
& \dot{E}^{\prime} q=\frac{1}{T^{\prime} \mathrm{do}}\left(E \mathrm{fd}-E^{\prime} q-\mathrm{id}\left(\mathrm{xd}-x^{\prime} d\right)\right) \\
& \dot{E} \mathrm{fd}=\frac{1}{T a}(k a(v \text { ref }-v t)-E \mathrm{fd})
\end{aligned}
$$

From the above equations, $\delta$ : is the angle of rotor, $\omega$ and $\omega b$ : are the rotor and synchronous speed, Pm: is the input mechanical power, $P_{e}$ : is output electrical power, D and M: are damping coefficient and machine inertia, $\mathrm{E}_{f d}, \dot{E}^{\prime} q$ and $E^{\prime} q$ : are the generator field, internal voltage of generator and transient generator, respectively, $\mathrm{T}^{\prime}{ }_{\text {do }}$ : is the time constant of field circuit, the reference voltage is Vref. Ka, Ta: are the gain and time constant of excitation system, respectively. The generator output power is written in terms of the q-axis as well as d-axis components of the armature current $i$, and terminal voltage $V_{t}$ as:

$$
\mathbf{P}_{\mathrm{e}}=\mathrm{v}_{\mathrm{td}} \mathbf{i}_{\mathrm{d}}+\mathrm{v}_{\mathrm{tq}} \mathbf{i}_{\mathrm{q}}
$$

\subsection{Linearized form of SMIB with UPFC}

The model of linear dynamic by linearization of non-linear model for the operating condition. Figure 1 illustrates the linearized model of the power system as given by [16]:

$$
\begin{aligned}
\Delta \dot{\delta} & =\omega b \Delta \omega \\
\Delta \dot{\omega} & =\frac{1}{M}(\Delta P m-\Delta P e-D \Delta \omega) \\
\Delta \dot{E}^{\prime} q & =\frac{1}{T^{\prime} d o}\left(\begin{array}{r}
\Delta E f d-\Delta E^{\prime} q \\
\left.-\Delta i d\left(x d-x^{\prime} d\right)\right)
\end{array}\right.
\end{aligned}
$$

$\Delta \dot{E} f d=\frac{1}{T a}(-k a \Delta v t-\Delta E f d)$ 
where:

$\Delta \mathrm{P} e=\mathrm{K} 1 \Delta \delta+\mathrm{K} 2 \Delta \mathrm{E}^{\prime} q+\mathrm{Kpd} \Delta \mathrm{vDC}+\mathrm{Kpe} \Delta \mathrm{m} E+\mathrm{Kp} \delta \mathrm{e} \Delta \delta E+\mathrm{Kpb} \Delta \mathrm{m} B+\mathrm{Kp} \delta \mathrm{b} \Delta \delta B$

$\Delta \mathrm{E}^{\prime} q=\mathrm{K} 4 \Delta \delta+\mathrm{K} 3 \Delta \mathrm{E}^{\prime} q+\mathrm{Kqd} \Delta \mathrm{vDC}+\mathrm{Kqe} \Delta \mathrm{m} E+\mathrm{Kq} \delta \mathrm{e} \Delta \delta E+\mathrm{Kqb} \Delta \mathrm{m} B+\mathrm{Kq} \delta \mathrm{b} \Delta \delta B$

$\Delta v t=\mathrm{K} 5 \Delta \delta+\mathrm{K} 6 \Delta \mathrm{E}^{\prime} q+\mathrm{Kvd} \Delta \mathrm{vDC}+\mathrm{Kve} \Delta \mathrm{m} E+\mathrm{Kv} \delta \mathrm{e} \Delta \delta E+\mathrm{Kvb} \Delta \mathrm{m} B+\mathrm{Kv} \delta \mathrm{b} \Delta \delta B$

$\Delta \dot{V}_{\mathrm{dc}}=\mathrm{K} 7 \Delta \delta \mathrm{E}+\mathrm{K} 8 \Delta \mathrm{E}^{\prime} q-\mathrm{K} 9 \Delta \mathrm{vDC}+\mathrm{Kce} \Delta \mathrm{m} E+\mathrm{Kc} \delta \mathrm{e} \Delta \delta E+\mathrm{Kcb} \Delta \mathrm{m} B+\mathrm{Kc} \delta \mathrm{b} \Delta \delta B$

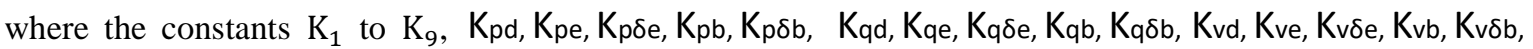
$\mathrm{K}_{c e}, \mathrm{~K}_{\mathrm{c} \delta e}, \mathrm{~K}_{\mathrm{cb}}$ and $\mathrm{K}_{\mathrm{c} \delta \mathrm{b}}$ are functions of the system coefficients and the initial operating coefficients. In state-space exemplification, these equations may be arrayed in concise formula as:

$$
\Delta \dot{X}=A \Delta X+B \Delta U
$$

$\Delta X=\left[\begin{array}{lllll}\Delta \delta & \Delta \omega & \Delta \mathrm{E}_{q}^{\prime} & \Delta \mathrm{E}_{\mathrm{fd}} & \Delta \mathrm{V}_{\mathrm{dc}}\end{array}\right]^{T}, \Delta \mathrm{U}=\left[\begin{array}{llll}\Delta \text { Upss } & \Delta \mathrm{U}_{\mathrm{mE}} \Delta \mathrm{U}_{\delta \mathrm{E}} & \Delta \mathrm{U}_{\mathrm{mB}} & \Delta \mathrm{U}_{\delta \mathrm{b}}\end{array}\right]^{T}$

The construction of the matrices $\mathrm{A}$ and $\mathrm{B}$ are:
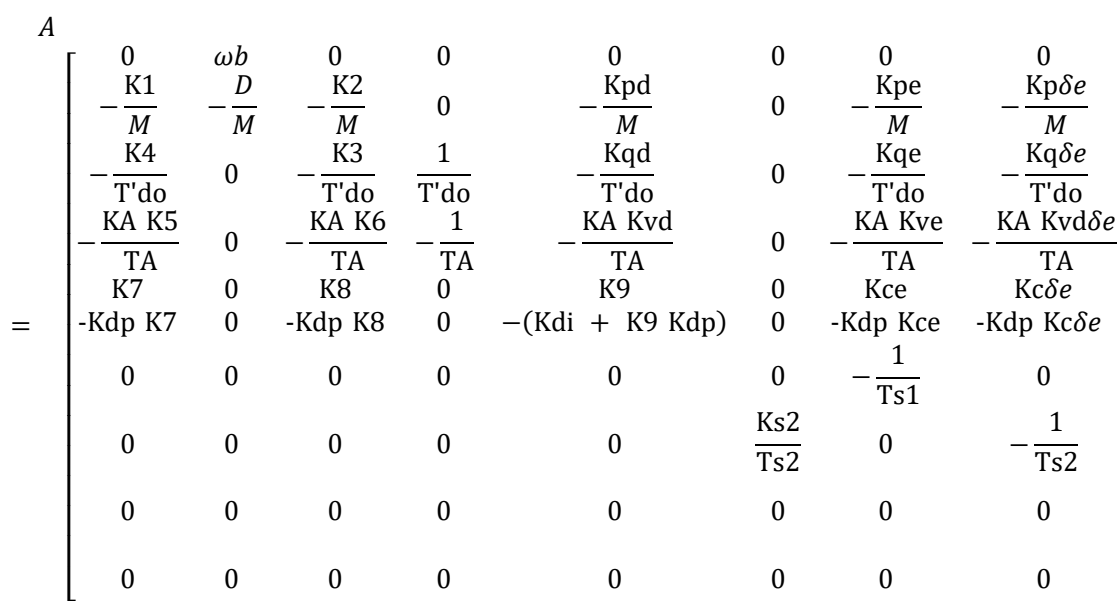

$-\frac{0}{M p b}$
$-\frac{\mathrm{Kqb}}{\mathrm{T} d \mathrm{do}}$
$-\frac{\mathrm{KA} \mathrm{Kvb}}{\mathrm{TA}}$
$\mathrm{Kcb}$
$-\mathrm{Kdp} \mathrm{Kcb}$

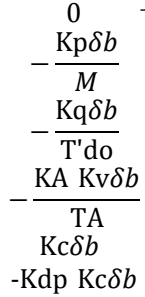

$$
\begin{gathered}
0 \\
\frac{\mathrm{Ks} 2}{\mathrm{Ts} 2} \\
0 \\
0
\end{gathered}
$$

0
0
$-\frac{1}{\mathrm{Ts} 3}$
0

0
0
0
$-\frac{1}{\mathrm{Ts} 4}$

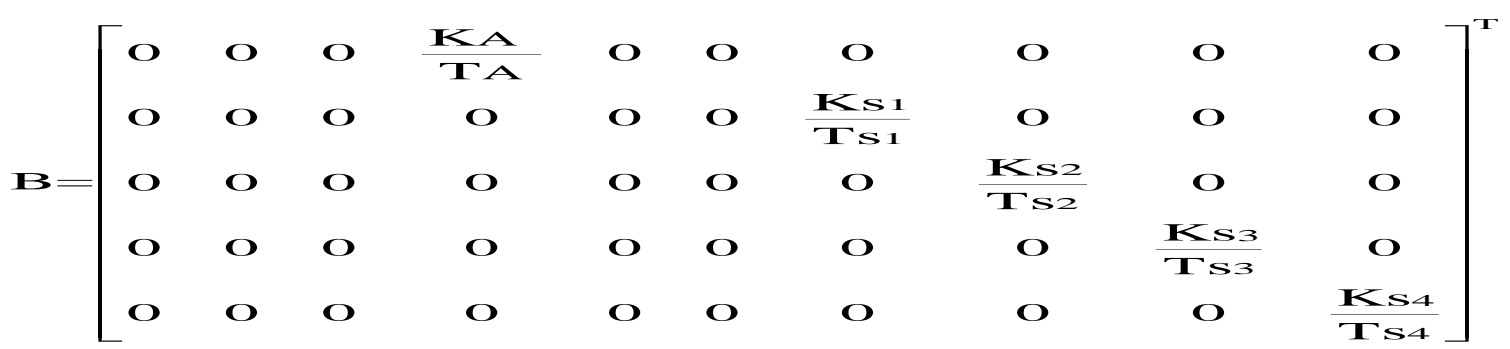

\subsection{Eigenvalues $(\lambda)$ of the system without controller}

By solving Ch. Equation $|\lambda I-A|=0$ utilizing MATLAB, system eigenvalues are obtained and displayed in Table 1. It can be directly understood from Table 1 that the performance of this system is unstable due to the existence of two positive damped modes $(\lambda 3)$ and $(\lambda 4)$ and requires a supplementary controller for stability.

Table 1. Eigenvalues $(\lambda)$ without controller

\begin{tabular}{cc}
\hline Eigenvalues $(\lambda)$ & Value \\
\hline${ }_{1} \lambda$ & $-18.2681+0.0000 \mathrm{i}$ \\
${ }_{2} \lambda$ & $-19.9252+0.0000 \mathrm{i}$ \\
$\lambda_{3} \& \lambda_{4}$ & $\mathbf{0 . 2 6 5 4} \pm \mathbf{2 . 6 2 8 8 i}$ \\
${ }_{5} \lambda$ & $-2.4425+0.0000 \mathrm{i}$ \\
$\lambda_{6} \& \lambda_{7}$ & $-0.0806 \pm 0.1829 \mathrm{i}$ \\
$\lambda_{8} \lambda_{9} \& \lambda_{10}$ & $-20.0000+0.0000 \mathrm{i}$ \\
\hline
\end{tabular}

Int J Elec \& Comp Eng, Vol. 10, No. 6, December 2020 : 6111 - 6121 


\section{THE POWER FLOW CONTROLLING DAMPING}

To damp LFO and ensure system stability, auxiliary control is adopted to the generator stimulation in the model of flow controller of the unified power-damping controller of power oscillation. The four control signal coefficients for the unified power flow controller $(\mathrm{mE}, \delta \mathrm{E}, \mathrm{mB}$, and $\delta \mathrm{B})$ be arrange so as to generate suitable damping torque as displayed in Figure 2. In this work, used one control signal parameter is excitation amplitude modulation ratio (i.e. $\mathrm{mE}$ ) so as to generate the proper damping and for dual-coordination design [17]. POD controller is like PSS as displayed in Figure 3. Where mad of main blocks of three inputs, gain, a washout and phase compensators.

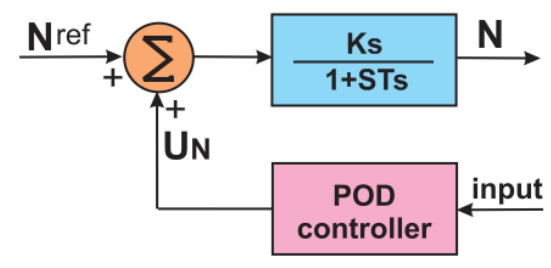

Figure 2. UPFC-POD controller

(1)

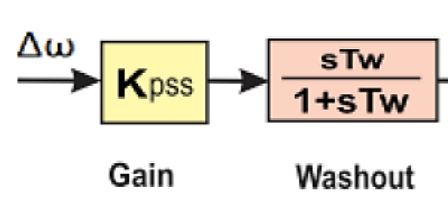

(2)

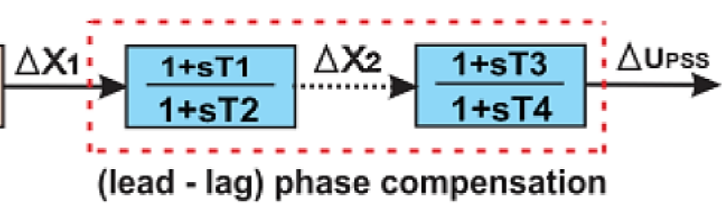

Figure 3. Block diagram of PSS or POD controller

The gain block use for determining the amount of damping the resulting from the PSS. The high pass filter is shown as the washout block using to remove the DC offset of the PSS or POD output and furthermore avoids the change of steady-state signal and the phase compensator block is used to supply appropriate phase-lead characteristic for compensating the phase lag among the generator electrical torque in addition to the exciter input. The Washout Time (Tw) must have a value in the choice of (1-20 s.). Tw equal to (10 sec), which are taken in the present study. The POD parameters are $\mathrm{K}_{\mathrm{PSS}}, \mathrm{T}_{1}, \mathrm{~T}_{2}, \mathrm{~T}_{3}$ and $\mathrm{T}_{4}$, to be calculated. Speed deviation $(\Delta \omega)$ is the POD input signal and $\Delta U_{N}$ is the output of the controller, where $\mathrm{K}_{\mathrm{PSS}}=\mathrm{PSS}$ and/or mE controllers, $\mathrm{i}=1,2,3,4[18]$.

\section{OBJECTIVE FUNCTION}

The main target of the technique based on optimization to enhance the power system stability to disorders at miscellaneous conditions of loading. It be reached by tuning damping of the controller parameters. The POD is a lead-lag type controller which can be presented as:

$$
\mathrm{U}(\mathrm{s})=\mathrm{G}(\mathrm{s}) \mathrm{Y}(\mathrm{s})
$$

where: $\mathrm{G}(\mathrm{s}), \mathrm{Y}(\mathrm{s}) \& \mathrm{U}(\mathrm{s})$ are the transfer function, input signal and output signal of POD controller, respectively.

In state-space mode, in (18) can be presented as:

$$
\mathrm{X}^{\cdot} \mathrm{C}=\mathrm{A}_{\mathrm{C}} \Delta \mathrm{X}_{\mathrm{C}}+\mathrm{B}_{\mathrm{C}} \Delta \mathrm{U}
$$

where: $\triangle \mathrm{XC}$ is state vector of the controller. By merging Eq. (17 \& 19), the closed loop system can be achieved.

$$
\Delta \mathrm{X}_{\mathrm{Cl}}^{\cdot}=\mathrm{A}_{\mathrm{Cl}} \Delta \mathrm{Xcl}
$$




$$
\begin{aligned}
& \Delta X c l=\left[\begin{array}{c}
\Delta X \\
\Delta X c
\end{array}\right] \\
& \zeta i=-\frac{\operatorname{Real}(\lambda i)}{|\lambda i|}
\end{aligned}
$$

The objective function is:

$$
J=\text { Min. }(\zeta i)
$$

Here, $\Delta X c l$ is the vector state, $\zeta i$ is the coefficient of damping of the $i^{\text {th }}$ eigenvalue and $\lambda i$ is the $i^{\text {th }}$ eigenvalue of the matrix of closed loop system. It is noticed that objective function $J$ calculates the minimum value of $\zeta i$ between wholly system modes $(\lambda i)$. The target process of optimization is applied for maximizing $J$ value so as to accomplish a suitable damping for wholly modes containing electromechanical mode, and maximum $J$ is examined within the restricted choice of POD controller parameters as:

$$
\begin{aligned}
& K_{\mathrm{R}}^{\min } \leq K_{\mathrm{R}} \leq K_{\mathrm{R}}^{\max }, \quad T_{\mathrm{R} i}^{m^{\min }} \leq T_{\mathrm{R} i} \leq T_{\mathrm{R} i}^{\max }, T_{\mathrm{RI}}^{\min } \leq T_{\mathrm{RI}} \leq T_{\mathrm{RI}}^{\max } \\
& \mathrm{R}=\mathrm{PSS} \text {, mE-POD (i.e. UPFC-POD), } \mathrm{i}=1,3, \text { and } \mathrm{I}=2,4 . \\
& \text { Typical ranges of } \mathrm{K}_{\mathrm{R}} \text { is }(0.01-100), T_{\mathrm{R} i} \text { is }(0.001-1) \text { and } T_{\mathrm{RI}} \text { is }(0.001-0.1) .
\end{aligned}
$$

\section{OPTIMIZATION TECHNIQUES}

The main target of optimization algorithm is to determine optimal parameters value of both independent controllers (PSS only) or (UPFC-POD only) and simultaneous coordinated designs among (PSS and UPFC-POD) to enhance system oscillations damping and dynamic stability performance for a SMIB. In this study, DEO and PSO algorithms are utilized for solving the described problem.

\section{1. (PSO) algorithm}

It is first introduced and developed by Eberhart and Kennedy in year 1995 [19]. The behavior of swarms of birds, each nominee solution to the optimization problem was represented randomly as a "particle" in the identity D-dimension space, and each group of particles contains a "population" [20, 21]. The position arranged for each particle in a hyperspace is stocked in a memory named "pbest", which is in link to fitted solution in each experience. Furthermore, the location arranged to the best value up to now amongst entirely the populated particles in the memory that is denoted as "gbest". The "pbest" and "gbest" changed for every iteration of the PSO algorithm, and every velocity of the particle is changed towards them randomly. The velocity and position of each agent are [22]:

$$
\begin{aligned}
& v \mathrm{i}^{\mathrm{k}+1}=\mathrm{w} \cdot v \mathrm{i}^{\mathrm{k}}+\mathrm{c}_{1} \cdot \mathrm{r}_{1} \cdot\left(\text { pbesti }-\mathrm{si}^{\mathrm{k}}\right)+\mathrm{c}_{2} \cdot \mathrm{r}_{2} \cdot(\text { gbesti - } \\
& \left.\mathrm{si}^{\mathrm{k}}\right) \\
& \mathrm{S}_{\mathrm{i}}{ }^{\mathrm{k}+1}=\mathrm{S}_{\mathrm{i}}{ }^{\mathrm{k}}+v_{\mathrm{i}}{ }^{\mathrm{k}+1}
\end{aligned}
$$

where, $\mathrm{S}$ is the position of agent, $v$ is the velocity, $\mathrm{k}$ is the iterations number, $\mathrm{w}$ depicts the weight, $\mathrm{c}_{1}, \mathrm{c}_{2}$ are the cognitive and asocial positive constants that utilize to pull every individual on the way to $p_{\text {best }}$ position and $g_{\text {best }}$ position within range [ 0 to 2.05] and $\mathrm{r}_{1}, \mathrm{r}_{2}$ are the two random numbers within limit [0 to 1].

\section{2. (DEO) algorithm}

Kaveh and Farhoudi have been developed and enhanced a new technique of optimization called the Dolphin echolocation optimization (DEO) method in year 2013 [23]. Dolphins can discover their environment by using the benefits of echolocation. The basic idea of DEO algorithm come from mimicking the behavior of Dolphins when hunting. The Dolphin can gift sound in the type of a tap in different locations and as soon as this sound hits something, many of the sound power is return back towards the Dolphin such as echoes. So, the Dolphin is listening to them and now wants to make a choice. Dolphin recognizes a distance to the baits and where they are. Tracing stage is begun and Dolphin move to bait, continue sending sound in addition to receiving echoes until Dolphin access the preys. During this approach, the probability of the hunting increases every time and search space reduced continuously. When dolphin received echoes from different locations, at this time the Dolphin can process and evaluate this information and decide to select the next step, which is a very essential step [24]. Figure 4 shows the process of DEO algorithm. 


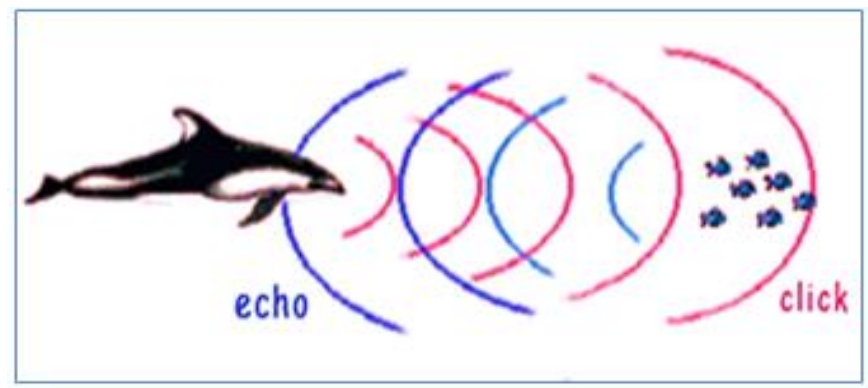

Figure 4. Real Dolphin catching its victim

\subsubsection{Mathematical formulation of the DEO algorithm} are [25]:

The typical flowchart of DEO technique is presented in Figure 5 and the steps of the tuning process

Step 1: Initialization

Choose the maximum number of loops $\mathrm{N}$, number of locations NL randomly and number of variables $\mathrm{NV}$ which are $\left(\mathrm{K}_{\mathrm{R}}, \mathrm{T}_{\mathrm{Ri}}\right.$ and $\left.\mathrm{T}_{\mathrm{RI}}\right)$ in the proposed controller (i.e. PSS or UPFC-POD). This step enclose creating $\mathrm{LNL}+\mathrm{NV}$ matrix. Maximum alternative number MA in the search space to creating alternative matrix with dimension [MAXNV].

Step 2: CF finding and predefining

Compute the PP of the loop utilizing following equation:

$$
\begin{aligned}
& \mathrm{PP}\left(\text { Loop }_{\mathrm{i}}\right)=\mathrm{PP}_{1}+(1 \\
&\left.-\mathrm{PP}_{1}\right) \frac{\text { Loopi }}{\text { power }-1} \\
&(\text { Loops Number })^{\text {power }}-1
\end{aligned}
$$

where, $\mathrm{PP}$ is the probability, $\mathrm{PP}_{1}=0.1$ is the first loop Convergence Factor $(\mathrm{CF})$ where the results are randomly chosen, Loop i number of the loop in which optimization process is performing as well as power is degree of the curve. Power $<1$ which generally offers best results.

Step 3: Fitness calculation

In this work, the suggested objective function for the controller has been calculated as following:

$J=\operatorname{Min} .(\zeta)$ : Objective function

$\operatorname{Max} .(J)$ : Fitness function

Step 4: Fitness accumulated (FA) Calculation

Compute FA and find $\mathrm{L}(\mathrm{i}, \mathrm{j})$ in $\mathrm{jth}$ column position of the matric of alternatives denoted as A. $X=-\operatorname{Re}$ to $\operatorname{Re}$

$$
\mathrm{AF}_{(\mathrm{A}+\mathrm{X}) \mathrm{j}}=(1 / \mathrm{Re}) *(\operatorname{Re}-|\mathrm{X}|) \text { Fitness }(\mathrm{i})+\mathrm{AF}_{(\mathrm{A}+\mathrm{Xij}) \mathrm{j}}
$$

From the above equation: $A F(A+X) j$ : is the Accumulative Fitness of the $(A+X)$. Re depicts the affected radius where AF of the alternative A's neighbours is influenced for their fitness then calculates the AF for every $j^{\text {th }}$ variable in $\mathrm{L}(\mathrm{i}, \mathrm{j})$ location by utilizing the Dolphin equation given in eq. 30 . This radius was chosen as being less that $1 / 4$ of the search space size. It is worth that the close age alternatives $(A+X<0$ or $A+X>L A j$, where $\mathrm{A}+\mathrm{X}$ is not a valid), the calculation of $\mathrm{AF}$ is performed by using a reflective characteristic. In order to hand out the search space alternative, a small amount of $\varepsilon$ is applied to the wholly groups as $\mathrm{AF}=\mathrm{AF}+\varepsilon$. Now, $\varepsilon$ is better to be less than any possible fitness.

Step 5: Finding best location

Find the best location, where will have finest $\mathrm{AF}$ and let $\mathrm{AF}$ for finest location alternative equal zero. Step 6: Determination of probability as well as allocation

Calculate the probability $\mathrm{P}(\mathrm{i}, \mathrm{j})$ as following:

$$
P(i, j)=\frac{A F i j}{\sum_{i=1}^{L A j} A F i j}
$$


Let probability equal to:

$P(i, j)=P P$ for wholly variables of the finest position.

$\mathrm{P}(\mathrm{i}, \mathrm{j})=\left(1-\mathrm{PP} \mathrm{loopi}_{\mathrm{i}}\right) \cdot \mathrm{P}(\mathrm{i}, \mathrm{j})$ else.

Step 7: Select location of the next loop

Modify the locations of the next loop according to allocated probability of its alternative.

Step 8: Reiteration

The ultimate criterion of termination is achieved or once the value of $\mathbf{J}$ is maximum, if yes stop the optimization and print the best results; otherwise, repeat steps 2 to 7 . The user-provided parameters for the DEO and PSO algorithms are tabulated in Table 2.

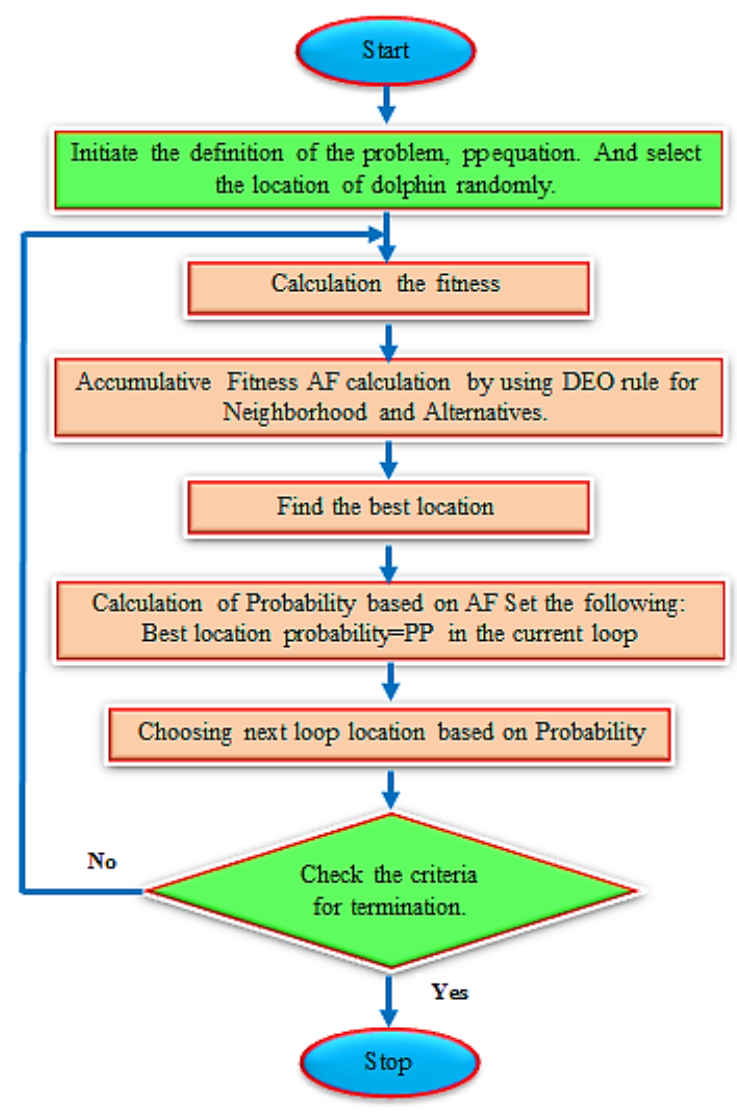

Figure 5. Flowchart of the DEO algorithm

Table 2. Algorithms proper parameters

\begin{tabular}{cccc}
\hline PSO & \multicolumn{3}{c}{ DEO } \\
\hline $\mathrm{N}$ ( No. of swarms) & 30 & NL (No. of location) & 30 \\
Variables & 5 & Variables & 5 \\
c1, c2 & 2 & Nalt. & 90 \\
w & 0.3 & Loops No. & 50 \\
Iteration & 50 & & \\
\hline
\end{tabular}

\section{SIMULATIONS RESULTS}

In this section, the capabilities of the presented dual and multiple coordinated designs are evaluated to improve the system's dynamic stability by damping the LFO. Figure 6 shows the speed deviation response without any controller is not stable without any controller and there is increasing of the oscillations. So as to obtain the optimal response of the PSS \& POD controller, use the DEO algorithm and it is compared with PSO. The final values of optimized parameters and damping ratio $(\zeta)$ are gives in Table 3.

Figure 7 displays SMIB's response to speed deviation with the traditional individual controller (i.e. PSS only). It can be seen that PSS controller has effective damping the system oscillations by using DEO algorithm compared to the PSO. Where the speed deviation responses via using DEO algorithm show that 
the parameters improved and they are higher than settling time in comparison to their PSO. Figure 8 displays SMIB's response to speed deviation with the proposed individual UPFC-POD controller, we selected excitation amplitude modulation ratio (i.e. channel $\mathrm{mE}$ only) to test the damping of oscillation. It can be seen that the channel is acceptable for damping oscillations.

Figure 9 illustrates the speed deviation responses of SMIB with the proposed coordinated design between PSS \& UPFC-POD (channel mEonly) simultaneously. It can be noticed that better dynamic response is achieved by the coordinated design between PSS \& UPFC-POD. Using DEO is most superior, which has fewer oscillations in addition to much quicker than PSO technique. Settling time is $(2 \mathrm{sec}$.$) as well as overshoot$ is $(0.00667$ p.u by DEO but PSO the settling time is $(6.62 \mathrm{sec}$.$) and overshoot is (0.009757$ p.u $)$. So, it can be noticed that the settling time and over shoot obtained by DEO is less than that obtained by PSO as demonstrated in Table 4.

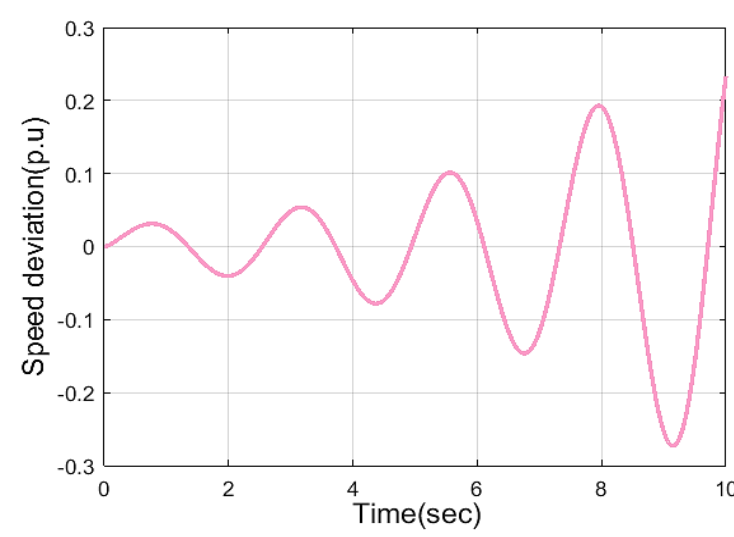

Figure 6. Speed variation $(\Delta \omega)$ without any controller

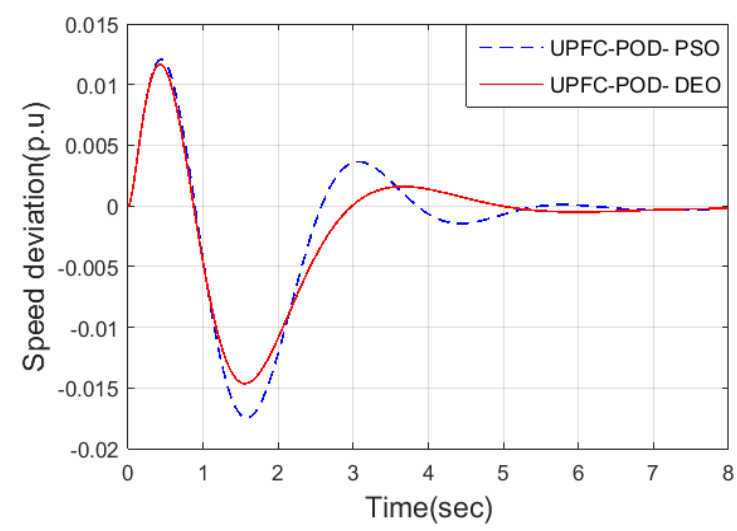

Figure 8. Speed variation $(\Delta \omega)$ with independently (UPFC-POD only) controller

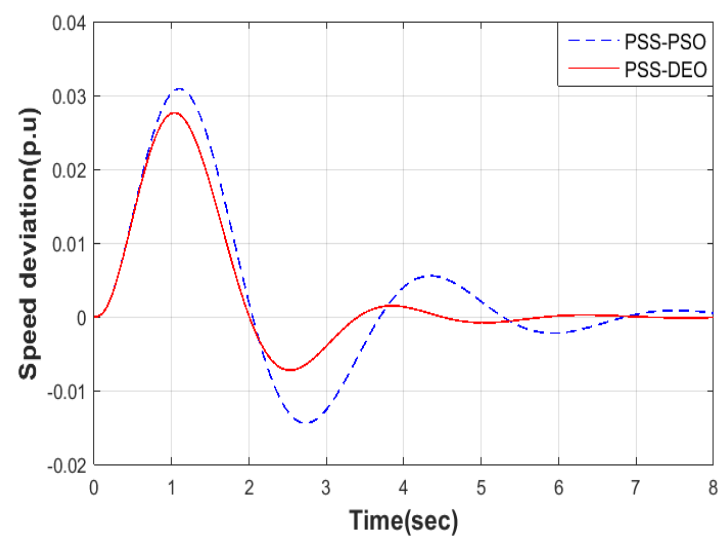

Figure 7. Speed variation $(\Delta \omega)$ with independently (PSS only) controller

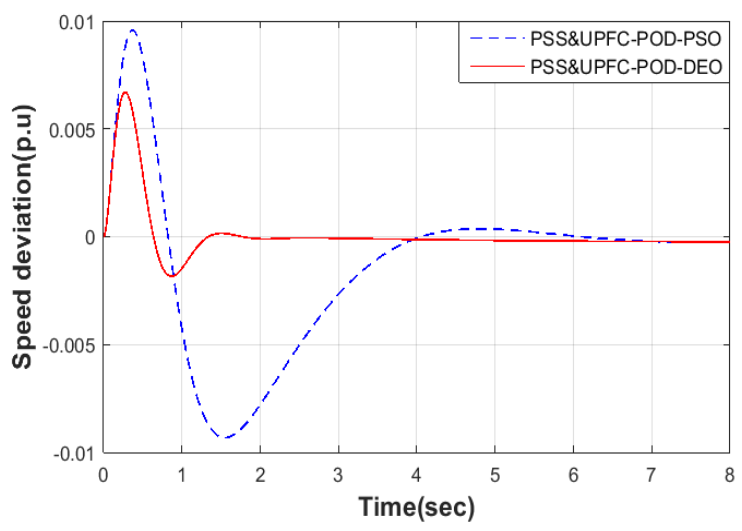

Figure 9. Speed variation $(\Delta \omega)$ with (PSS and UPFC-POD simultaneous) controllers

Table 3. Specifications of speed deviation responses for PSO and DEO algorithms

\begin{tabular}{|c|c|c|c|c|c|c|c|}
\hline Controller type & & Zeta $(\zeta)$ & $\mathrm{K}$ & $\mathrm{T}_{1}$ (Sec.) & $\mathrm{T}_{2}$ (Sec.) & $\mathrm{T}_{3}$ (Sec.) & $\mathrm{T}_{4}$ (Sec.) \\
\hline \multirow[t]{2}{*}{ PSS } & PSO & 0.2791850 & 6.5857 & 0.0135 & 0.1153 & 0.0010 & 0.8370 \\
\hline & DEO & 0.3135269 & 13.9866 & 0.0012 & 0.8779 & 0.0009 & 0.9820 \\
\hline \multirow[t]{2}{*}{ mE-POD } & PSO & 0.4808169 & 18.9789 & 0.0990 & 0.4031 & 0.0918 & 0.9966 \\
\hline & DEO & 0.5011140 & 27.8727 & 0.0996 & 0.8932 & 0.0980 & 0.9454 \\
\hline \multirow{4}{*}{ PSS $^{*} \&$ mE-POD ${ }^{* * *}$} & & & $17.0757^{*}$ & $0.0842^{*}$ & $0.9381^{*}$ & $0.0214^{*}$ & $0.2529^{*}$ \\
\hline & PSO & 0.6381390 & $43.3396^{\text {** }}$ & $0.0054^{* *}$ & $0.4837^{* *}$ & $0.0516^{* *}$ & $0.9138^{* *}$ \\
\hline & DEO & ( 7101294 & $67.2977^{*}$ & $0.0033^{*}$ & $0.8838^{*}$ & $0.0021^{*}$ & $0.7244^{*}$ \\
\hline & DEO & 0.7191294 & $84.4493^{\text {** }}$ & $0.0072^{* *}$ & $0.3829^{* *}$ & $0.0059^{* * *}$ & $0.8764^{* *}$ \\
\hline
\end{tabular}


Table 4. Specifications of speed deviation responses for PSO and DEO algorithms

\begin{tabular}{cccc}
\hline \multicolumn{2}{c}{ Controller type } & Settling time (Sec.) & Over-Shoot \\
\hline \multirow{2}{*}{ PSS } & PSO & 0.03067 & 7.8 \\
& DEO & 0.02699 & 7 \\
mE-POD & PSO & 0.01208 & 6.7 \\
\multirow{2}{*}{ PSS\& mE-POD } & DEO & 0.01165 & 6 \\
& PSO & 0.009757 & 6.62 \\
\hline
\end{tabular}

\section{CONCLUSION}

The present study focuses on low frequency damping oscillations by individual and furthermore through dual design of coordination between PSS and UPFC-POD in SMIB system. The optimal tuning parameter problem of individual controller design or multiple damping controllers in the coordinating design is converted into an optimization problem. DEO algorithm employed as a new optimization technique for robust and optimized calculations to search and tune for optimal parameters settings of controllers in both independent controllers (PSS only) or (UPFC-POD only) and simultaneous dual-coordinated designs between (PSS and UPFC-POD) based on the given objective function via maximizing $J$ of the minimum damping ratio so as to accomplish the suitable damping for all complex eigenvalues $(\lambda i)$ for a SMIB. The simulation results confirmed that the DEO provide optimal or very close to the optimal results and robust effective in damping of LFO of individual and coordinated designs compared with PSO technique. In addition, using DEO achieved shortest settling time, minimum overshoot, provide higher LFO damping as well as advance the stability of the system best than PSO algorithm. Furthermore, a synchronized design of multiple damping stabilizers i.e. PSS \& UPFC-POD controller offer a better damping of LFO compared to individual controllers i.e. PSS or UPFC-POD only. Thus, the controllers with DEO are achieved best dynamic stability response in both individual and multiple controllers in addition to the best damping of LFO compared to PSO technique.

\section{APPENDIX}

Power system parameters

\begin{tabular}{ll}
\hline Generator & $\mathrm{M}=8, \mathrm{D}=0, \mathrm{~T}{ }^{\prime} \mathrm{do}=5.044, \mathrm{Xq}=0.6, \mathrm{Xd}=1, \mathrm{X}^{\prime} \mathrm{d}=0.3$ \\
Excitation & $\mathrm{K}_{\mathrm{A}}=10, \mathrm{~T}_{\mathrm{A}}=0.05$ \\
Transmission line & $\mathrm{XtE}=0.1, \mathrm{XBV}=0.6$ \\
Operating condition & $\mathrm{Pe}=0.8, \mathrm{Vt}=1, \mathrm{Vb}=1$ \\
UPFC Transformers & $\mathrm{XE}=0.1, \mathrm{XB}=0.1$ \\
Parameters of DC link & $\mathrm{VDC}=2, \mathrm{CDC}=1$ \\
UPFC & $\mathrm{mE}=0.4013, \delta_{\mathrm{E}}=-85.3478^{0}, \mathrm{~m}_{\mathrm{B}}=0.0789,, \delta_{\mathrm{B}}=-78.217^{0}$ \\
& $\mathrm{Ks}=1, \mathrm{Ts}=0.05$. \\
\hline
\end{tabular}

\section{REFERENCES}

[1] Sethi, I., Sharma, K. K., and Verma, S., "Low frequency oscillation in power system:a survey," International Journal of Recent Research Aspects, vol. 2, no. 3, pp. 110-117, 2015.

[2] Chaudhari, P.B. and Patel, M.V., "Design of power system stabilizer (PSS) to enhance power system stability in power system," International Journal of Engineering Research and Technology, vol. 5, no. 3, pp. 339-341, 2016.

[3] Khanchi, S., and Garg, V. K., "Unified Power Flow Controller (TSFAC Device): A Review," International Journal of Engineering Research and Applications (IJERA), vol. 3, no. 4, pp. 1430-1435, 2013.

[4] Y. Kumari, A. Gupta, S. P. Bihari, R. Chaubey, and B. Sehgal, "Performance and Analysis of Reactive Power Compensation by Unified Power Flow Controller," Indonesian Journal of Electrical Engineering and Informatics (IJEEI), vol. 3, no. 3, pp. 141-149, 2015.

[5] N. Tambey, and M. L. Kothari, "Damping of power system oscillations with unified power flow controller (UPFC)," IEE Proc.-Gener. Transm. Distrib., vol. 150, no. 2, pp. 129-140, Mar. 2003.

[6] N. Tambey, and M. L. Kothari, "Unified Power Flow controller (UPFC) Based Damping Controllers for Damping Low Frequency Oscillations in a Power System," Meeting held at Ranchi, vol 84, Jun. 2003.

[7] Ganesh, C., Prasad, P. B., and Gopal, G. V., "Transient Stability Enhancement during Damping of Low Frequency Oscillations of a Multi-Machine Power System Using Adaptive Neuro-Fuzzy Controller for TSFAC devices," International Journal of Engineering Research and Development, vol. 10, no. 7, pp. 25-35, 2014.

[8] Sedighizadeh M., Sarvi, M., Minooie, B, and Akbari, M., "Power System Stability Enhancement Using a NSPSO Designed UPFC Damping Controller," International Science Press, vol. 5, no. 2, pp. 125-141, 2013.

[9] Tapin, L., Mehta, R. K., "Low Frequency Oscillations in Power Systems: A Review," SSRG International Journal of Electrical and Electronics Engineering, vol. 1, no. 4, pp. 6-17, 2014. 
[10] Safari, A., Shayeghi, H., and Jalilzadeh, S., "Robust Coordinated Design of UPFC Damping Controller and PSS Using Chaotic Optimization Algorithm," Journal of Iranian Association of Electrical and Electronics Engineers, vol. 12, no. 3, pp. 1-7, 2015.

[11] J. Guo, M. L. Crow, and J. Sarangapani, "An improved UPFC control for oscillation damping," IEEE transactions on power systems, vol. 24, pp. 288-296, 2009.

[12] T. Jena, M. K. Debnath and S. K. Sanyal, "Optimal fuzzy-PID controller with derivative filter for load frequency control including UPFC and SMES," International Journal of Electrical and Computer Engineering (IJECE), vol. 9, no. 4, pp. 2813-2821, 2019.

[13] Tripathi, S. K., "Power System Stability Enhancement By UPFC Based Power Oscillation Damping Controller," International Research Journal of Engineering and Technology, vol. 4, no. 5, pp. 1107-1113, 2017.

[14] Banaei, M. R., Seyed-Shenava, S. J.and Farahbakhsh, P., "Dynamic stability enhancement of power system based on a typical unified power flow controllers using imperialist competitive algorithm," Ain Shams Engineering Journal, vol. 5, no. 3, pp. 691-702, 2014.

[15] Taithai, R. and Oonsivilai, A., "Optimal based damping controllers of unified power flow controller using adaptive tabu search," International Journal of Electrical and Computer Engineering (IJECE), vol. 6, no. 12, pp. 1739-1741, 2012.

[16] Hussain, A. N., Malek, F., Rashid, M. A., Mohamed, I., and Mohd Affendi, N. A., "Optimal Coordinated Design of Multiple Damping Controllers Based on PSS and UPFC Device to Improve Dynamic Stability in the Power System," Hindawi Publishing Corporation Mathematical Problems in Engineering, vol. 2013, pp. 1-15, 2013.

[17] Eslami, M., Shareef, H., Mohamed, A., and Khajehzadeh, M., "Coordinated Design of UPFC and PSS to improve power system stability," Przegląd Elektrotechniczny, pp. 153-158, 2013.

[18] Saxena, V., Rajeshwari, C. S., and Prakash, S., "Mitigation of Low Frequency Oscillation Phenomenon in Power System by Implementing Adaptive Fuzzy Logic Controlled Power System Stabilizer," International Journal of Emerging Technology and Advanced Engineering, vol. 4, no. 12, pp. 351-355, 2014.

[19] A. N. Hussain, A. A. Abdullah, and O. M. Neda, "Modified Particle Swarm Optimization for Solution of Reactive Power Dispatch," Research Journal of Applied Sciences, Engineering and Technology, vol. 15, no. 8, pp. 316-327, 2018.

[20] T. A. Khan, M. Alam, M. J. Tahir, K. Kadir, Z. Shahid and M. S Mazliham, "Optimized health parameters using PSO: a cost effective RFID based wearable gadget with less false alarm rate," Indonesian Journal of Electrical Engineering and Computer Science (IJEECS), vol. 15, no. 1, pp. 230-239, 2019.

[21] A. A. Abdullah, A. N. Hussain and O. M. Neda, "Reactive Power Optimization Based on Artificial Intelligence," International Journal of Applied Engineering Research, vol. 13, no. 8, pp. 5978-5988, 2018.

[22] B. Pati and S. B. Karajgi, "Optimized placement of multiple FACTS devices using PSO and CSA algorithms," International Journal of Electrical and Computer Engineering (IJECE), vol. 10, no. 4, pp. 3350-3357, 2020.

[23] Kaveh, A., and Farhoudi, N., "A new optimization method: Dolphin echolocation," Advances in Engineering Software, vol. 59, pp. 53-70, 2013.

[24] Kaveh, A., and Hosseini, P., "A Simplified Dolphin Echolocation Optimization Method For Optimum Design of Trusses," International journal of optimization in civil engineering, vol. 4, no. 3, pp. 381-397, 2014.

[25] Kaveh, A., and Farhoudi, N., "Dolphin Echolocation Optimization: ntinuous search space," Advances in Computational Design, vol. 1, no. 2, pp. 175-194, 2016.

\section{BIOGRAPHY OF AUTHOR}

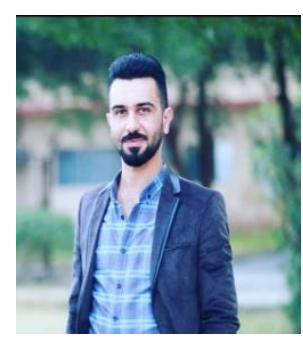

Omar Muhammed Neda was born in Babylon, Iraq on Octobar 6, 1988. He received his B.Sc. in Electrical Power Engineering Department, Al-Mussaib Engineering Technical College, Al-Furat Al-Awsat Technical University Babylon, Iraq, in 2010 and M.Sc. also in Electrical Power Engineering Department, Electrical Engineering Technical College at Middle Technical University. His current research interests include power system operation and control, power electronics, electric machine, robust control and Intelligent Optimization. 